\title{
An Italian Innovative Small-Scale Approach to Promote the Conscious Consumption of Healthy Food
}

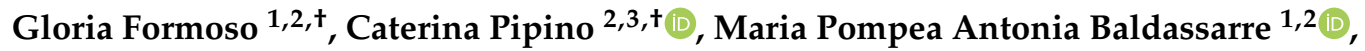 \\ Piero Del Boccio ${ }^{2,4}$, Mirco Zucchelli ${ }^{2,3}$, Nicola D'Alessandro ${ }^{5}$ (D) Lucia Tonucci $^{6}$, \\ Angelo Cichelli ${ }^{2}$, Assunta Pandolfi ${ }^{2,3}$ and Natalia Di Pietro ${ }^{2,3, *}$ \\ 1 Department of Medicine and Aging Sciences, University G. d'Annunzio of Chieti-Pescara, 66100 Chieti, Italy; \\ g.formoso@unich.it (G.F.); marbaldassarre@gmail.com (M.P.A.B.) \\ 2 Center for Advanced Studies and Technology-CAST (ex CeSI-MeT), University G. d'Annunzio of \\ Chieti-Pescara, 66100 Chieti, Italy; c.pipino@unich.it (C.P.); p.delboccio@unich.it (P.D.B.); \\ m.zucchelli@unich.it (M.Z.); cichelli@unich.it (A.C.); assunta.pandolfi@unich.it (A.P.) \\ 3 Department of Medical, Oral and Biotechnological Sciences, University G. d'Annunzio of Chieti-Pescara, \\ 66100 Chieti, Italy \\ 4 Department of Pharmacy, University G. d'Annunzio of Chieti-Pescara, 66100 Chieti, Italy \\ 5 Department of Engineering and Geology, University G. d'Annunzio of Chieti-Pescara, 66100 Chieti, Italy; \\ nicola.dalessandro@unich.it \\ 6 Department of Philosophical, Educational and Economic Sciences, University G. d'Annunzio of \\ Chieti-Pescara, 66100 Chieti, Italy; 1.tonucci@unich.it \\ * Correspondence: natalia.dipietro@unich.it; Tel.: +39-0871541424 \\ + These authors contributed equally.
}

Received: 9 July 2020; Accepted: 13 August 2020; Published: 15 August 2020

check for updates

Featured Application: The SANI small-scale approach may offer a great methodological opportunity to improve the food environment and promote healthy and conscious food consumption through a new nutritional educational approach, which lays the foundation for future application in a wider population.

\begin{abstract}
An unhealthy diet is considered to be one of the main causes for increases in obesity and chronic diseases. Food choices are frequently influenced by food systems and environments along with the availability and affordability of healthy and sustainable food. In this context, a major contemporary challenge lies in improving these aspects in order to support healthy dietary choices. Hence, to address this issue, here, we propose a small-scale approach called SANI (Italian for "healthy") which involves experts in science and marketing. Two typical agri-foods of the Abruzzo area (center of Italy), tomato sauce and extra virgin olive oil, are characterized as high-quality products in terms of their nutrient content, absence of chemical contaminants (chromatographic, spectrophotometric, and magnetic resonance techniques), and ecological footprint (lifecycle assessment and carbon footprint). Hence, their consumption is promoted, with strict attention being paid to several aspects of the food system, such as production, processing, distribution, labeling, and promotion, as well as marketing strategies and dissemination activities. Overall, these SANI actions, especially labeling and dissemination, have proven to be a valuable learning tool for consumers moving toward more conscious consumption, which can be extended and applied to additional food products. Future applications of similar research strategies in a wider context could positively affect human and environmental health.
\end{abstract}

Keywords: healthy food; Mediterranean diet; food system; sustainability; conscious consumption 


\section{Introduction}

In order to promote and maintain good health throughout the course of life, it is necessary to adopt a healthy diet as well as a healthy lifestyle. Unfortunately, life changes determined by industrialization, urbanization, economic development, and market globalization have had a significant negative impact on population health and nutritional status, leading to a global dietary transition [1]. While the standard of living has improved, food availability has expanded, with consequences in terms of unhealthy dietary patterns (e.g., high consumption of processed meat- and plant-based foods, sodium, sugar, and saturated fats and low consumption of fruit and vegetables, whole grains, fibers, legumes, fish, and nuts) [2]. This, together with sedentary habits, smoking, alcohol consumption, and weight gain, has led to an increase in the prevalence of obesity and numerous other chronic diseases [3].

Furthermore, as recently demonstrated, unhealthy food is often less sustainable, with a negative impact on the environment which, in turn, negatively affects human health $[4,5]$.

In this regard, the Mediterranean diet (MD) represents a high-quality dietary pattern which, as commonly represented graphically by the MD pyramid, includes the consumption of extra virgin olive oil (main source of monosaturated fatty acids, to be used for all culinary purposes); high consumption of plant-derived foods (fresh fruits, vegetables, legumes, and tree nuts); moderate-to-high consumption of fish, whole-grain cereal, and red wine (with meals); and reduced consumption of red and processed meat, cheese, butter, whole-fat dairy, sugar-sweetened beverages, biscuits, and cake [6]. Furthermore, the MD has been recognized since the 1990s as the most healthy diet by both the World Health Organization (WHO) and the Food and Agriculture Organization of the United Nations (FAO), and since 2010, it has been listed by the United Nations Educational, Scientific, and Cultural Organization (UNESCO) as an intangible cultural heritage of humanity $[7,8]$.

The MD is also recognized as an example of sustainability, as it respects the natural environment, generally represented as a double "food and environmental" pyramid. Indeed, there is a connection between good eating habits and a positive contribution to environmental sustainability [9]. The environmental pyramid roughly mirrors the food pyramid, but upside down. The double "food and environmental pyramid" suggests that food recommended for consumption in higher quantities, especially with regard to the MD, has a lower impact on the environment. Food advised for consumption in smaller quantities has the greatest impact on the environment. Thus, two different but equally important goals—-health and environmental protection—fit into a single food model (Figure 1) [10,11].

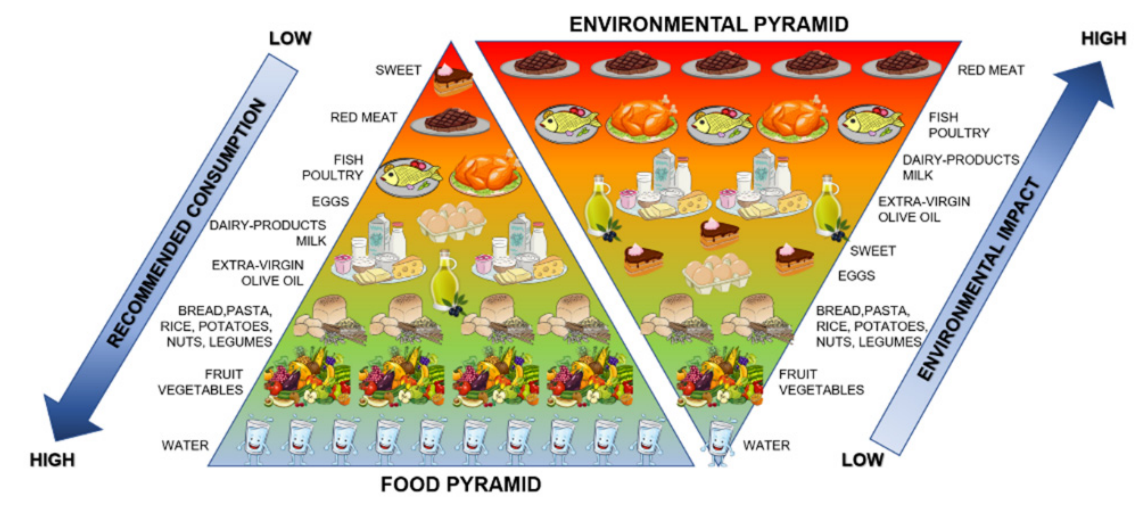

Figure 1. Double "food and environmental" pyramid.

Therefore, it is necessary to steer consumers towards an informed choice of healthy and sustainable food consumption [12]. Indeed, together with several previous studies [13-15], a recent review examining several articles published from 2017 to 2019 regarding food choices and nutrition found that, starting from childhood to adulthood, food education is the main strategy to improve choices [16].

Furthermore, nutritional knowledge is an important and decisive aspect that also influences the eating habits of the elderly [17]. Therefore, given that nutrition is an essential component of 
healthy aging, a critical aspect in promoting optimal nutrition and health throughout life, including in old age, is to ensure the availability of safe and adequate foods [9]. However, alongside this, multi-level innovation-including policy, private sector, public health, general community-is needed as well as individual-level approaches. Together, these aspects would allow for the development of a new, healthier, and more sustainable food system with positive effects on human health and the environment [18]. Indeed, one major contemporary challenge is to improve the food system, which refers to the elements and activities related to food production, processing, distribution, preparation, consumption, and food environments in order to make healthy foods available and affordable to consumers [19]. Therefore, beyond paying attention to the nutritional quality of naturally healthy foods, it is necessary to develop a strategy sharpening all key aspects of food supply chains, food environments, and consumer behavior $[19,20]$.

In this regard, cities offer great opportunities to improve food environments and the eating habits of residents [20-22], particularly in Mediterranean cities, which have unique characteristics in terms of small food shops and public markets whose accessibility is essential for stimulating eating and lifestyle habits towards more healthy profiles. Moreover, it should be taken into account that by $2050,66 \%$ of the world's population will live in cities [23].

However, it should be considered that large cities also present many fast food and full-service restaurants, and the number of bars/pubs and liquor stores that have been found positively associated with obesity and abdominal obesity [24].

In this complex scenario, we propose an Italian innovative small-scale approach as a useful model to educate and steer consumers towards conscious and healthy food choices, providing better characterization of some Italian local agri-food products typical of the MD in terms of nutrient content, chemical food contaminants, and environmental impact, and to promote these foods through dissemination of results and via innovative marketing channels.

Previous studies have suggested that improving product quality and the appearance of the store could potentially influence residents' food purchase decisions, though these studies did not adopt a broad-spectrum approach [25].

The SANI (Italian for "healthy") approach, developed for the first time here, has the main goal of providing education on the conscious consumption of local, healthy, and sustainable products using a combination of different skills from the field of agriculture, academia, marketing, communication, and technological tools. All of this may have the following positive repercussions covering all fields: (i) producers can appreciate the quality of their products better, becoming aware of the content of specific nutrients and their environmental impact; (ii) universities can develop new experimental protocols, and professors and researchers can play an important role in the dissemination process; and (iii) there will be an increase in the sale of products considered to be healthy in local retail specialty stores. This approach might steer consumers toward conscious food choices from sustainable and local food systems and could be implemented to more products and extended to a wider population, hopefully with consequent positive feedback for human health.

Last but not least, our study, adopting the multidisciplinary approach described above, intends to fill the gaps of previous monodisciplinary research [26], which often overlooks some aspects of the complex network of determinants in the food choice system.

\section{Materials and Methods}

\subsection{Description of SANI General Approach}

The general objective of the SANI small-scale approach was to characterize some local agri-food products typical of the MD in terms of their nutrient content, chemical food contaminants, and environmental impact, and to promote them through dissemination of results and via innovative marketing channels. 
To achieve this, the SANI strategy required the coordination of various activities-ranging from the agricultural sphere to the scientific and marketing spheres- that result from the knowledge and skills of the SANI partners (represented as a series of gears in Figure 2), which were as follows: (1) producers (local farmers); (2) academic research groups (universities) focused on food analysis, lifecycle assessment (LCA), and with expertise in the study of nutritional molecules [27-30]; (3) a consulting and training center (C\&T Center, a local society) specialized in organizing training in communication, marketing, and professional updating courses; and (4) a local retail specialty store located in an Italian medium-sized urban area (population 200,000-500,000), which played the role of the principal investigator of the funded SANI project.

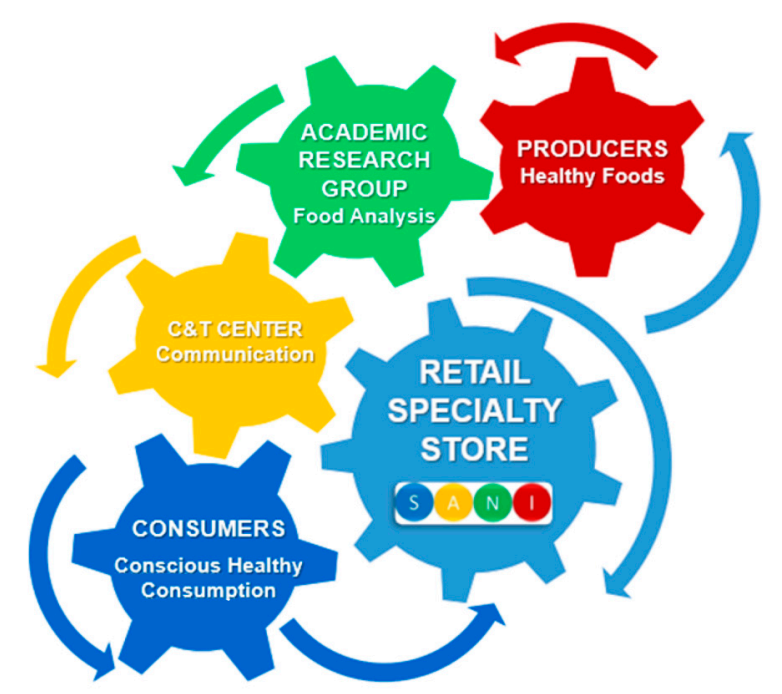

Figure 2. SANI (Italian for "healthy") partners and activities.

\subsection{Evaluation of Specific Nutritional Molecules and Chemical Food Contaminants in Selected Products}

As a small-scale Italian approach, the analyses focused on two highly consumed, healthy foods in the Mediterranean area and, in particular, on valuable and exclusive local product varieties of the Abruzzo region (center of Italy)—extra virgin olive oil (EVOO, produced by an oil mill located in the hills of the province of Chieti, Abruzzo) and tomato sauce (made from the tomato "pera d'Abruzzo", a typical variety of the Abruzzo region registered in the SIAN Plant Variety Register, Cod. 3399 SAAB-CRA). The research groups involved in the SANI strategy have technical scientific skills regarding chemical analysis of the nutraceutical compounds and toxic substances possibly present in food. Over the years, they have developed analytical methods for the qualitative and quantitative determination of different bioactive compounds, such as polyphenols, vitamin E, and carotenoids, using chromatographic, spectrophotometric, and magnetic resonance techniques [31-34]. For the SANI approach, attention has mainly been focused on the content of three bioactive compounds, namely, polyphenols, vitamin E, and carotenoids. These compounds have demonstrated antioxidant, anti-inflammatory, and anti-tumor activities that are responsible for the efficient prevention of numerous diseases (e.g., atherosclerosis, cardiovascular, neurodegenerative, and chronic intestinal diseases) $[29,35,36]$. In this regard, we determined the content of polyphenols and vitamin E in EVOO, and lycopene, $\beta$-carotene, and vitamin $\mathrm{E}$ in tomato sauce $[32,37,38]$.

Furthermore, the levels of chemical food contaminants harmful for human health, including fatty acid esters of 2-chloropropane-1,3-diol (2-MCPD), 3-chloropropane-1,2-diol (3-MCPD), and glycidol, were assessed [39]. These contaminants, as we have previously shown, are mainly formed at high temperatures as a result of the refining process but are also usually derived from poor quality raw material [34].

In parallel, the AOCS Official Method Cd 29c-13 was used for the determination of 2-MCPD, 3-MCPD, and glycidol in EVOO [34,40]. 


\subsection{Assessment of the Environmental Impact in Selected Products}

In general, the environmental impact depends on many factors, including treatments during the production, packaging, marketing, and consumption processes in terms of energy expenditure and employment of resources. Usually, three indicators are used to quantify this impact, namely, the ecological footprint, measuring the Earth's capacity to regenerate the resources used to produce a single food; the carbon footprint, measuring the greenhouse gas emissions (GHGEs) during its lifecycle; and the water footprint, which measures the consumption of water for each specific food.

As the research groups involved in the SANI approach have specific experience in the analysis of the environmental impact of the process using the lifecycle assessment (LCA) and carbon footprint [41,42], the latter was determined as an index of the environmental impact of the selected products.

The carbon footprint of EVOO was evaluated taking into consideration the following processing steps: agricultural phase (all mechanical processing, and phytosanitary treatments and the management of the aerial part of the crops), collection and transport phase in oil mills, and extraction and packaging (into 5-liter steel containers) phases. The evaluation of the carbon footprint of tomato sauce included the development of the tomato seedling; cultivation, harvesting, and transport of tomatoes; washing and sauce production; and packaging, distribution, and end-of-life of packaging.

\subsection{Identification of Health Claims and Development of SANI Labels}

In line with the rules governing the nutrition and health claims sector [43], nutrient quality labels (SANI labels) and a sustainability label (carbon footprint label) were designed. Briefly, we chose easily distinguishable colors and icons as a result of collaboration with labeling experts, designers, and nutritionists. The carbon footprint label was designed with the same characteristics as those already available on the web and on commercial products, i.e., a foot on a green background and with the $\mathrm{CO}_{2}$ symbol (chemical symbol for carbon dioxide) to indicate GHGEs. For the nutritional labels, they were designed on the basis of the following characteristics: (i) clear label (a transparent, comprehensive, easy to read, and information-rich label) and (ii) social label (a label at the service of people who know exactly what they are buying and are able to trace the entire supply chain). Indeed, these were equipped with a quick response code ( $Q R$ code) useful for providing real-time information to consumers (Figure 3).

\subsection{Determination of Customer Shopping Habits}

The shopping habits of consumers who follow a balanced diet and/or require specific nutritional needs (food intolerances, sports, diabetes, aging, obesity, hypercholesterolemia, pregnancy, menopause, nephropathy, etc.), as well as the perception of the meaning of healthy food vs. unhealthy food and natural food vs. artificial food have been identified through the development of collected metadata (through testing conducted by different customer relationship management companies, like Perfex, Infusionsoft, Hubsport, and Salesforce-free trial versions) by the local retail project partner. To study customer behavior towards natural food, the local retail project shop conducted a preliminary interview on 10 randomly selected regular customers. This allowed for building the following survey to be taken by 192 adults, $78 \%$ of whom were women and $22 \%$ were men, all aged between 19 and 64 years ( $8 \%$ aged $19-24,13 \%$ aged $25-34,22 \%$ aged $35-44,34 \%$ aged $44-54,16 \%$ aged $55-64$, and $7 \%$ older than 64 years) and with different working statuses ( $66 \%$ freelancer and employees, $5 \%$ entrepreneurs, $5 \%$ housewives, $10 \%$ students, $7 \%$ retired, and $7 \%$ unemployed). The survey was designed to test the interviewees' knowledge on general wellbeing and healthy eating by completing a simple questionnaire.

Moreover, the retail specialty store classified its customers by applying a psychographic method, the eight values and lifestyles (VALS), which allowed for designing an innovative marketing strategy by using several analysis tools such as Javelin Board, the Value Proposition Canvas, and selling funnel marketing. These tools focused on the following key elements for consumers: improvement of physical and economic food access through specific custom fidelity programs oriented to prize the consumption 
of healthy food; innovative services useful to increase healthy food consumption, focused on the project mission; and an explicit food offer based on nutritional quality and healthy safety using the SANI label (the trademark "Bollino SANI" (SANI label), which was registered with deposit no. 302019000012369, on 21 February 2019, Figure 3) [19,20].

\subsection{SANI Approach Communication, Dissemination and Marketing Strategy}

The communication of the obtained data and the dissemination of the SANI small-scale strategy represent two key points of the project. They were implemented using the following tools: (1) a blog containing several informative articles (namely, referring to scientific publications) regarding the beneficial effect of the consumption of specific healthy products; (2) a dedicated SANI project web page; (3) a SANI project Facebook page; (4) web videos on the SANI project covering several topics on healthy nutrition, published on different online platforms (Facebook, YouTube, and the SANI project page); (5) several public dissemination events to promote the SANI project at local fair events; (6) distribution of informative flyers on SANI; (7) organization of educational meetings for consumers; and (8) organization of academic meetings. Physicians, nutritionists, and naturopaths as well as different types of associations (professional, consumer, and social operators' associations) were involved in the dissemination activities listed above.

\section{Results and Discussion}

The first activity of the SANI approach was to identify some highly consumed "km zero" agri-food products in the retail specialty store that involved local farms. Among them, local EVOO and tomato sauce were identified as being worthy of further investigation. Indeed, these two valuable and exclusive local product varieties of extra virgin olive oil (EVOO; produced by an oil mill located in the hills of the province of Chieti, Abruzzo) and tomato sauce (made from the tomato "pera d'Abruzzo", a typical variety of the Abruzzo region registered in the SIAN Plant Variety Register code 3399 SAAB-CRA) are highly consumed in the Abruzzo region, especially by people who know their organoleptic properties. However, they have never been fully characterized prior to the SANI study in terms of their specific nutrient contents, the absence of chemical contaminants, and their ecological footprints.

As shown in Table 1, these products presented a specific quantity of nutritional molecules (vitamin $\mathrm{E}$, carotenoids, and polyphenols), the total absence of specific chemical contaminants (2-MCPD, 3-MCPD, and glycidol) harmful for human health, and both were within the range corresponding to a low environmental impact on the Mediterranean area, as shown by their carbon footprint evaluations.

In more detail, the results revealed a high quality of local EVOO, demonstrated by the presence of vitamin E (alpha-tocopherol $229.5 \mathrm{mg} / \mathrm{kg}$ ) and an adequate polyphenol content $(360 \mathrm{mg} / \mathrm{kg}$ ). In the tomato sauce, the presence of specific carotenoids (beta-carotene $0.12 \mathrm{mg} / 100 \mathrm{~g}$ and lycopene $7.57 \mathrm{mg} / 100 \mathrm{~g}$ ) and vitamin E (alpha-tocopherol $1.14 \mathrm{mg} / 100 \mathrm{~g}$ ) were observed. This allowed us to confirm that the two local products naturally contain bioactive compounds beneficial for human health and, thus, can possibly be defined as "high-quality foods". This aspect is even more relevant if we consider the total absence of chemical contaminants, such as glycidyl fatty acids esters which, as demonstrated by previous studies, are harmful to human health and are generally present in processed oils and food-based products containing oil [44]. In this regard, it has been shown that palm oil has a high content of chemical contaminants as a result of the transformation process, while crude or unrefined oils and fats, such as extra virgin olive oil, either do not contain chemical contaminants or contain merely trace amounts $[34,44,45]$.

However, it is important to specify that these evaluations were not performed for comparing the quality of the selected products to other brands, but mainly aimed to support the consumer toward conscious consumption through innovative methodology characterized by the easy readability of the specific nutritional properties of the product (e.g., through colorful SANI labels). 
Beyond the nutritional value of the foods in terms of their carbohydrate, protein, fat, and fiber contents, with a direct impact on physical fitness and health, attention should also be paid to the fact that each food has an environmental impact and by considering its entire lifecycle.

The analysis performed on EVOO, together with the information gathered from the oil mill, revealed that the production of this specific local EVOO had a total emission of approximatively $6 \mathrm{~kg}$ $\mathrm{CO}_{2} \mathrm{eq}$ (carbon dioxide equivalent) for $5 \mathrm{~L}$ (e.g., $1.2 \mathrm{~kg}$ per liter). Thus, EVOO emission falls in the lower part of the carbon footprint average range in the Mediterranean area $\left(10.51 \mathrm{~kg} \mathrm{CO}_{2}\right.$ eq per liter of olive oil, in line with the world level) [42,46-48]. The carbon footprint measured for the tomato sauce resulted of about $1.3 \mathrm{~kg} \mathrm{CO}_{2}$ eq per liter of product packaged in glass, thus in a good impact range considering that, depending on the packaging materials and the size used, the carbon footprint average ranged between 0.3 and $2.28 \mathrm{~kg} \mathrm{CO}_{2}$ eq per liter [49,50]. Hence, the carbon footprint assessment of the two described products showed that both fall within the range corresponding to a low impact.

This suggests that the use of local products represents a positive factor that together with the improvement of other components (e.g., reduction in the use of fossil fuels), could contribute to a healthy environment. In this regard, our approach fits well into the contemporary challenge aimed at expanding research on the production and consumption of sustainable local food [51]. The consumption of sustainable products would have positive effects on various aspects, first environmental, but also social, economic, and human health aspects [51]. As for the last aspect, it is known that a healthy environment is the basis of a healthy life, and an unhealthy environment contributes to the onset of various non-communicable diseases (NCD), such as stroke, heart disease, cancer, and other chronic diseases [52].

Table 1. SANI products: content of valuable compounds and their carbon footprint.

\begin{tabular}{ccccccc}
\hline PRODUCT & Vitamin E & Polyphenols & $\beta$-Carotene & Lycopene & $\begin{array}{c}\text { 2-MCDP } \\
\text { 3-MCDP } \\
\text { Glycidol }\end{array}$ & $\mathbf{C O}_{2} \mathbf{e q} / \mathbf{L}$ \\
\hline EVOO & $229.5 \mathrm{mg} / \mathrm{kg}$ & $360 \mathrm{mg} / \mathrm{kg}$ & - & - & absence & $1.2 \mathrm{~kg}$ \\
\hline Tomato sauce & $1.14 \mathrm{mg} / 100 \mathrm{~g}$ & - & $0.12 \mathrm{mg} / 100 \mathrm{~g}$ & $7.57 \mathrm{mg} / 100 \mathrm{~g}$ & absence & $1.3 \mathrm{~kg}$ \\
\hline
\end{tabular}

Based on these results and the rules governing the health claims sector [43], nutrient quality labels (SANI labels) and a sustainability label (carbon footprint label) were designed that were easily recognizable to consumers.

As shown in Figure 3, the SANI labels consisted of specific colorful marks that were assigned to each healthy nutritional component. Interestingly, these labels were equipped with a QR code, intended to be useful to consumers by allowing them to access real-time information in order to enrich their shopping carts with many healthy products, making it possible to achieve a balanced, healthy, complete, and sustainable diet.

This, along with communication of the obtained data, the dissemination activity, an innovative online e-commerce platform, and through optimal shelf marketing, led to a considerable increase in conscious purchasing. Indeed, before the SANI survey, the results showed that people would like to live a healthy life by consuming natural food, but that their knowledge about healthy natural food was conflicting, thus affecting their choices. Indeed, an analysis of the distribution of the responses to the questionnaire (Table 2) based on age groups was conducted (Figure 4), and this revealed how age can affect certain choices and awareness. For example, most interviewees ( $60 \%$ of the total) considered natural food as "whole food, without any human intervention", or "as natural, thus you can trust" (10\%). Only $30 \%$ of interviewees considered natural foods as "organic foods" rich in healthy nutritional components. 


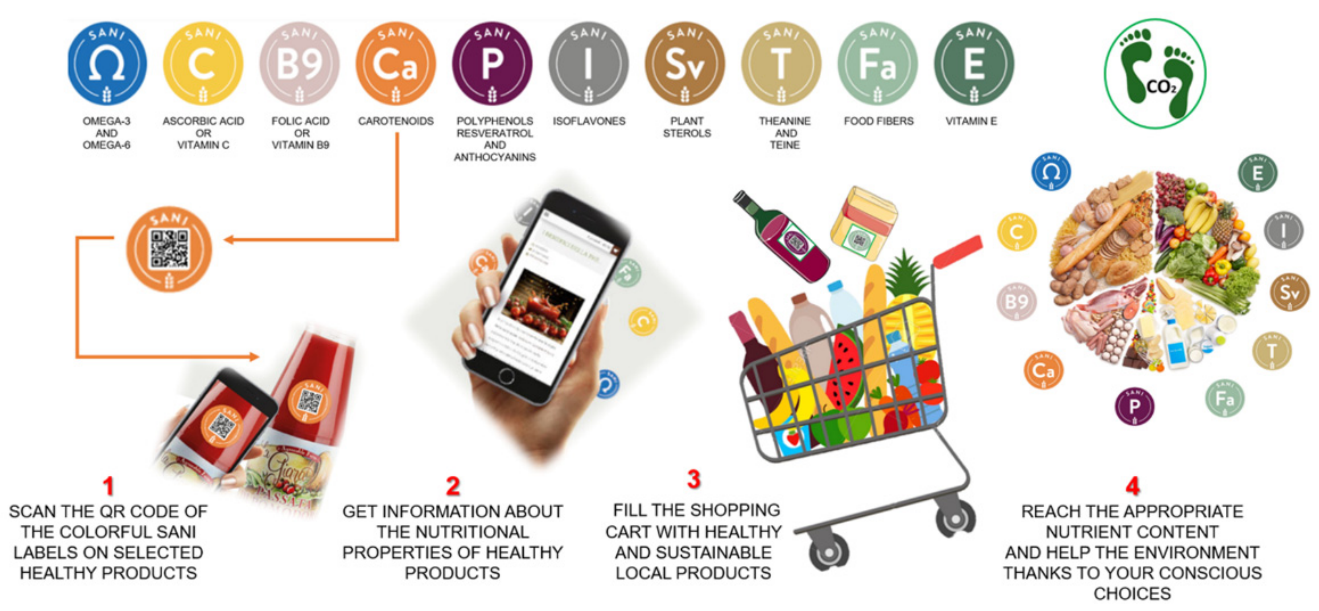

Figure 3. SANI labels and marketing approach. Following the directions of the SANI marketing approach (1-4), the shopping cart is enriched with many healthy products, each with a different label to help achieve a balanced, healthy, complete, and sustainable diet.

Table 2. SANI questionnaire.

\begin{tabular}{|c|c|}
\hline \multirow{2}{*}{ 1. Are you ...? } & A) Female \\
\hline & B) Male \\
\hline \multirow{4}{*}{ 2. What is your occupation? } & A) A professional \\
\hline & B) An employee \\
\hline & C) An entrepreneur \\
\hline & D) Other \\
\hline \multirow{6}{*}{ 3. Age } & A) $25-30$ \\
\hline & B) $31-40$ \\
\hline & C) $41-50$ \\
\hline & D) $51-60$ \\
\hline & E) $61-70$ \\
\hline & F) Other \\
\hline
\end{tabular}

A) I think they are good for my health

4. What do you think about natural products?
B) I think I should consume them or use them every day

C) I think it is okay if I consume them or use them occasionally

D) I think industrial products convince me more

\section{E) Other}

A) Whole food, without any human intervention

$$
\text { B) Organic food }
$$

\section{What does natural food mean to you?}

D) Natural, thus you can trust it

E) A new way to sell products

\section{F) Other}

A) I would go to a beauty center

6. What would you do to live in a state of wellness?

\section{B) I would go to a gym}

C) I would go on holiday in a farmhouse or in a spa

D) I would use natural products for my diet and/or my esthetic 


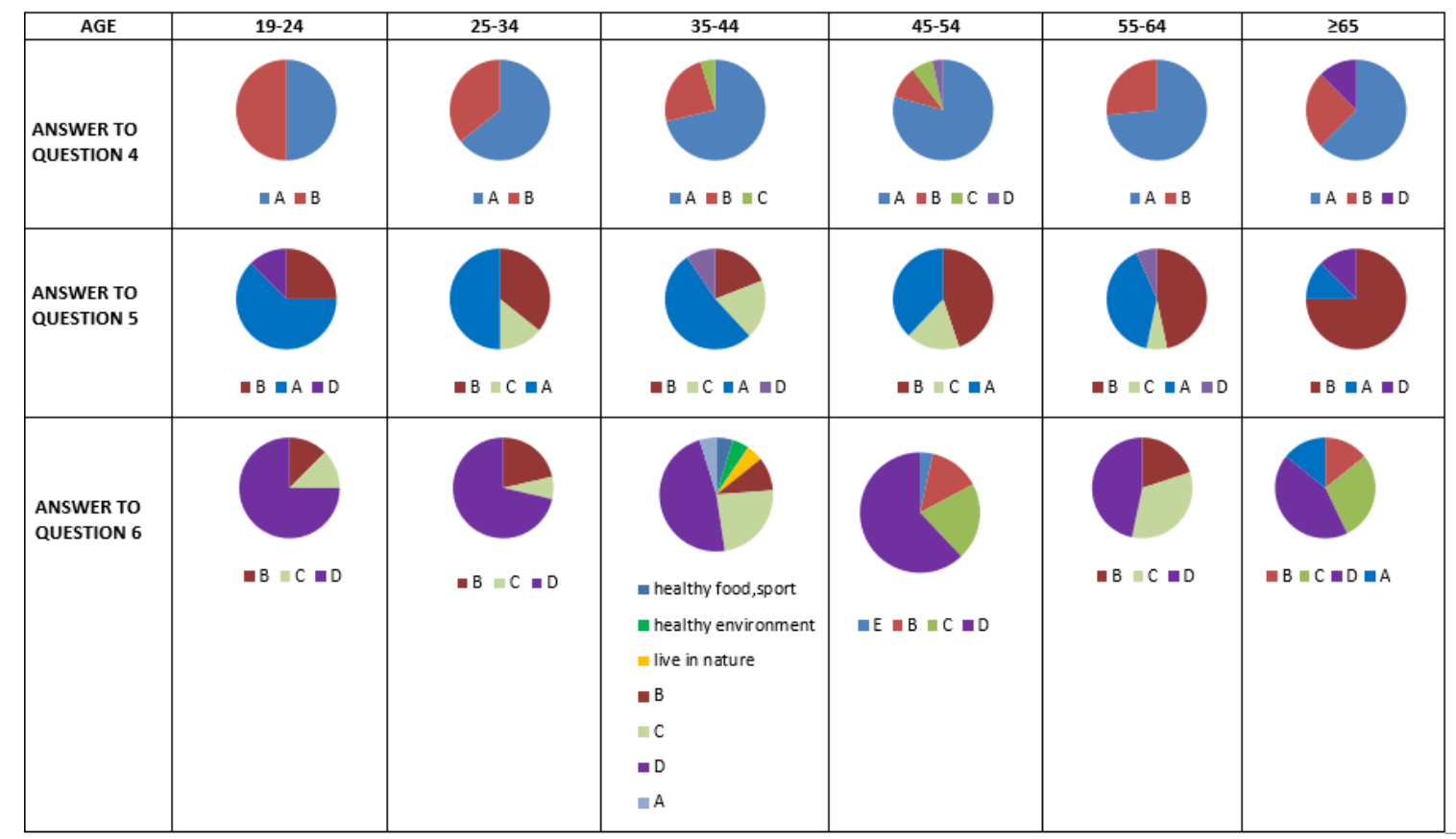

Figure 4. Distribution of responses to the SANI survey questionnaire by age group. Question 4: What do you think about natural products? Question 5: What does natural food mean to you? Question 6: What would you do to live in wellness? Refer to Table 2 for the answers.

Following the SANI approach, a significant increase in labeled SANI product sales was found during both 2017-2018 (number of sales 183; 95\% confidence interval (CI): 157.45-211.52, $p<0.05$; Poisson distribution analysis) and 2018-2019 (number of sales 245; 95\% CI: 212.47-274.49, $p<0.05$; Poisson distribution analysis) compared with the sales in 2016-2017 (number of sales 150; 95\% CI: 126.96-176.02; Poisson distribution analysis) before implementation of the SANI approach. However, it is important to point out that these data are not intended to highlight an increase in sales in terms of earnings but to indicate the increased sale of products considered to be healthy as a consequence of people becoming oriented towards healthier product consumption through SANI.

Indeed, in accordance with a previously published research [53], the results of the SANI approach confirm that consumers buy certain organic and local foods because they are perceived as being healthier, fresher, more respectful of the environment, and favorable to the local economy compared with conventional products.

In this regard, one of the main future purposes will be to extend our approach to many other local products, but also for other Italian products in a wider context.

SANI was experimentally applied, as a small-scale approach, in a single city of the Abruzzo region, but given that farms located throughout the region were involved, its repercussions were wider. Furthermore, the project was part of public policies on innovation in the Abruzzo region with the aim of reducing the environmental effects of human activities in this region, and was interconnected with other projects conducted by the research groups of the SANI strategy and funded by the Italian Ministry of Scientific Research (CL.USTER A.GRIFOOD CL.AN Pros.It; MIUR, 2012) and the European Union (PEFCR pilot project on olive oil; EU, 2014). The purpose of both grants was to develop technologies and knowledge for safer food production with high-quality features and a low environmental impact of food products typical of the MD, such as olive oil, wine, pasta, and dairy products. Future application of similar research strategies in a wider context could positively affect human and environmental health. 


\section{Conclusions and Implications}

The increasing prevalence of obesity and chronic diseases demands that action be taken in recognition of the perilous direction many consumers are taking regarding their food choices [54-56]. Many aspects of current lifestyles should be improved, together with a new and profound renewal of the food system. Recently, the High-Level Panel of Experts on Food Security and Nutrition identified three constituent elements of food systems, namely, food supply chains, food environments, and consumer behavior [19].

The SANI approach deals with all of these aspects and allows for improvements in some of these areas specific to food systems, with positive effects on human and environmental health thanks to the promotion of conscious consumption. In more detail, the specific nutrient content and environmental impact of two varieties of agri-food typical of the Abruzzo region were assessed, which allowed for creating specific labels associated with technological tools. Furthermore, a key aspect which allowed for reaching the main objective, was the dissemination of the approach and results. Finally, the SANI approach was proven to be a valuable learning and growth opportunity for all of the involved subjects (producer, academia, distributor, and customer).

This suggests that implementation of this small-scale strategy in a wider context, such as cities or countries, could be very useful. This would involve both short- and long-term goals. In the short-term, it may be extended to other cities in the Abruzzo region and to cities of other Italian regions, while as a long-term objective, this strategy could be extended to Mediterranean countries and, subsequently, to a wider territory. In conclusion, we believe that the pilot study proposed here lays the foundation for further development in a larger population, thus leading to successful improvements in all aspects of food systems and increased conscious consumption of healthy and sustainable foods.

\section{Limitations}

Although the SANI approach may represent a valid tool to respond to the current challenges regarding the improvement of the food system, focusing attention on human health in terms of nutrition and environmental sustainability, it has some flaws and shortcomings.

First, the possible difficulty of reorganizing an active network between various partners (producers, academic research groups, consulting and training centers, consumers, and retail specialty stores) in a scenario other than that of the SANI strategy. Second, SANI knowledge should reach a wider population that, outside the Mediterranean area, could be difficult to apply as a result of different eating habits and lifestyles [57]. These actions, as mentioned above, should comprise both short- and long-term targets. Among these, assessing the long-term potential benefits on human health and the environment could require more skills and people to be involved.

Additionally, further research will be necessary to improve the informative method on health claims (such as labeling improvement) in order to help consumers with choosing products for specific and customized dietary needs. Indeed, a weakness of SANI labels is that they indicate exclusively specific nutrients, which are contained in high quantities in the products, associated with a technological tool (QR code) that allows to get real-time information about the nutrient properties. A label that presents a complete profiling of all macronutrients and micronutrients, together with an indication of the unhealthy ones for human health, such as those already reported in the NutriScore and SAIN-LIM system [58,59], could be more useful for consumers.

Another limitation may be the ability of older people to use technological tools (such as smartphones, tablets, and computers), as these skills were required especially during the communication, dissemination, and marketing phases of the SANI project. As for our small-scale project, the elderly population was only $23 \%$, and they had assistance from the staff of the specialty retail store in order to get information about the products of interest during purchases. However, this aspect is expected to be resolved in the near future, with directed efforts already underway [60]. 
In conclusion, in spite of these limitations, the SANI project offers a great methodological opportunity to improve the food environment and to promote conscious healthy dietary consumption through a novel nutritional educational approach.

Author Contributions: Conceptualization, N.D.P. and A.P.; methodology, N.D. and A.C.; formal analysis, P.D.B.; investigation, L.T. and M.Z.; resources, N.D. and P.D.B.; data curation, M.P.A.B.; writing (original draft preparation), N.D.P., G.F., and C.P.; supervision, N.D.P.; project administration, A.P.; funding acquisition, A.P. and A.C. All authors have read and agreed to the published version of the manuscript.

Funding: This research was funded by SAper NutrIre (SANI; Por Fesr Abruzzo 2014-2020 Asse I Determinazione), grant number 39 DPG013/12222017.

Acknowledgments: The authors thank the SANI network partners: Francesco Cuddemi, Paola Renzetti, Elisa Antonioni, and Marianna Belfatto.

Conflicts of Interest: The authors declare no conflict of interest. The funders had no role in the design of the study; in the collection, analyses, or interpretation of data; in the writing of the manuscript; or in the decision to publish the results.

\section{References}

1. Tilman, D.; Clark, M. Global diets link environmental sustainability and human health. Nature 2014, 515, 518-522. [CrossRef]

2. Cuevas Garciá-Dorado, S.; Cornselsen, L.; Smith, R.; Walls, H. Economic globalization, nutrition and health: A review of quantitative evidence. Global. Health 2019, 15, 1-19. [CrossRef]

3. Bruins, M.J.; Van Dael, P.; Eggersdorfer, M. The Role of Nutrients in Reducing the Risk for Noncommunicable Diseases during Aging. Nutrients 2019, 11, 85. [CrossRef]

4. Canavan, C.R.; Noor, R.A.; Golden, C.D.; Juma, C.; Fawzi, W. Sustainable food systems for optimal planetary health. Trans. R. Soc. Trop. Med. Hyg. 2017, 111, 238-240. [CrossRef] [PubMed]

5. Clark, M.A.; Springmann, M.; Hill, J.; Tilman, D. Multiple health and environmental impacts of foods. Proc. Natl. Acad. Sci. USA 2019, 116, 23357-23362. [CrossRef] [PubMed]

6. Vitiello, V.; Germani, A.; Capuzzo Dolcetta, E.; Donini, L.M.; del Balzo, V. The new modern mediterranean diet italian pyramid. Ann. Ig. 2016, 28, 179-186. [PubMed]

7. Bach-Faig, A.; Berry, E.M.; Lairon, D.; Reguant, J.; Trichopoulou, A.; Dernini, S.; Medina, F.X.; Battino, M.; Belahsen, R.; Miranda, G.; et al. Mediterranean diet pyramid today. Science and cultural updates. Public Health Nutr. 2011, 14, 2274-2284. [CrossRef] [PubMed]

8. Altomare, R.; Cacciabaudo, F.; Damiano, G.; Palumbo, V.D.; Gioviale, M.C.; Bellavia, M.; Tomasello, G.; Lo Monte, A.I. The mediterranean diet: A history of health. Iran. J. Public Health 2013, 42, 449-457. [PubMed]

9. Grosso, G.; Fresán, U.; Bes-rastrollo, M.; Marventano, S.; Galvano, F. Environmental impact of dietary choices: Role of the mediterranean and other dietary patterns in an Italian cohort. Int. J. Environ. Res. Public Health 2020, 17, 1468. [CrossRef]

10. Lăcătușu, C.M.; Grigorescu, E.D.; Floria, M.; Onofriescu, A.; Mihai, B.M. The mediterranean diet: From an environment-driven food culture to an emerging medical prescription. Int. J. Environ. Res. Public Health 2019, 16, 942. [CrossRef]

11. Ruini, L.F.; Ciati, R.; Pratesi, C.A.; Marino, M.; Principato, L.; Vannuzzi, E. Working toward Healthy and Sustainable Diets: The "Double Pyramid Model" Developed by the Barilla Center for Food and Nutrition to Raise Awareness about the Environmental and Nutritional Impact of Foods. Front. Nutr. 2015, 2, 9. [CrossRef] [PubMed]

12. Drewnowski, A.; Finley, J.; Hess, J.M.; Ingram, J.; Miller, G.; Peters, C. Toward Healthy Diets from Sustainable Food Systems. Curr. Dev. Nutr. 2020, 4, 1-12. [CrossRef] [PubMed]

13. Buttriss, J.; Stanner, S.; McKevith, B.; Nugent, A.P.; Kelly, C.; Phillips, F.; Theobald, H.E. Successful ways to modify food choice: Lessons from the literature. Nutr. Bull. 2004, 29, 333-343. [CrossRef]

14. Chadwick, P.M.; Crawford, C.; Ly, L. Human food choice and nutritional interventions. Nutr. Bull. 2013, 38, 36-42. [CrossRef]

15. Hardcastle, S.J.; Thøgersen-Ntoumani, C.; Chatzisarantis, N.L.D. Food choice and nutrition: A social psychological perspective. Nutrients 2015, 7, 8712-8715. [CrossRef] [PubMed] 
16. Perez-Cueto, F.J.A. An umbrella review of systematic reviews on food choice and nutrition published between 2017 and-2019. Nutrients 2019, 11, 2398. [CrossRef]

17. Dunneram, Y.; Jeewon, R. Determinants of eating habits among older adults. Prog. Nutr. 2015, 17, $274-283$.

18. Anderson, C.A.M.; Thorndike, A.N.; Lichtenstein, A.H.; Van Horn, L.; Kris-Etherton, P.M.; Foraker, R.; Spees, C. Innovation to Create a Healthy and Sustainable Food System: A Science Advisory from the American Heart Association. Circulation 2019, 139, 1025-1032. [CrossRef]

19. Mehta, L.; Cordeiro-Netto, O.; Oweis, T.; Ringler, C.; Schreiner, B.; Varghese, S. The High Level Panel of Experts on Food Security and Nutrition of the Committee on World Food Security HLPE; Technical Report for Nutrition and Food Systems: Rome, Italy, 2017.

20. Franco, M.; Diez Roux, A.V.; Glass, T.A.; Caballero, B.; Brancati, F.L. Neighborhood characteristics and availability of healthy foods in Baltimore. Am. J. Prev. Med. 2008, 35, 561-567. [CrossRef]

21. Camargo, D.F.M.; Belon, A.P.; Marín-León, L.; Do Nascimento Jacinto de Souza, B.F.; Pérez-Escamilla, R.; Segall-Corrêa, A.M. Comparing food environment and food purchase in areas with low and high prevalence of obesity: Data from a mapping, in-store audit, and population-based survey. Cad. Saude Publica 2019, 35, 1-12. [CrossRef]

22. Glanz, K.; Yaroch, A.L. Strategies for increasing fruit and vegetable intake in grocery stores and communities: Policy, pricing, and environmental change. Prev. Med. Baltim. 2004, 39, 75-80. [CrossRef] [PubMed]

23. Visioli, F.; Franco, M.; Toledo, E.; Luchsinger, J.; Willett, W.C.; Hu, F.B.; Martinez-Gonzalez, M.A. Olive oil and prevention of chronic diseases: Summary of an International conference. Nutr. Metab. Cardiovasc. Dis. 2018, 28, 649-656. [CrossRef] [PubMed]

24. Walker, B.B.; Shashank, A.; Gasevic, D.; Schuurman, N.; Poirier, P.; Teo, K.; Rangarajan, S.; Yusuf, S.; Lear, S.A. The Local Food Environment and Obesity: Evidence from Three Cities. Obesity 2020, 28, 40-45. [CrossRef]

25. Martin, K.S.; Ghosh, D.; Page, M.; Wolff, M.; McMinimee, K.; Zhang, M. What role do local grocery stores play in urban food environments? A case study of Hartford-Connecticut. PLoS ONE 2014, 9, e94033. [CrossRef] [PubMed]

26. Perez-Cueto, F.J.A.; Olsen, A. The Multifaceted Dimensions of Food Choice and Nutrition. Nutrients 2020, 12, 502. [CrossRef] [PubMed]

27. Castellano, I.; Di Tomo, P.; Di Pietro, N.; Mandatori, D.; Pipino, C.; Formoso, G.; Napolitano, A.; Palumbo, A.; Pandolfi, A. Anti-Inflammatory Activity of Marine Ovothiol A in an In Vitro Model of Endothelial Dysfunction Induced by Hyperglycemia. Oxid. Med. Cell. Longev. 2018, 2018, 1-12. [CrossRef]

28. Di Tomo, P.; Canali, R.; Ciavardelli, D.; Di Silvestre, S.; De Marco, A.; Giardinelli, A.; Pipino, C.; Di Pietro, N.; Virgili, F.; Pandolfi, A. $\beta$-Carotene and lycopene affect endothelial response to TNF- $\alpha$ reducing nitro-oxidative stress and interaction with monocytes. Mol. Nutr. Food Res. 2012, 56, 217-227. [CrossRef]

29. Di Pietro, N.; Di Tomo, P.; Pandofi, A. Carotenoids in cardiovascular disease prevention. JSM Atheroscler 2016, 1, 1002.

30. Ucci, M.; Di Tomo, P.; Tritschler, F.; Cordone, V.G.P.; Lanuti, P.; Bologna, G.; Di Silvestre, S.; Di Pietro, N.; Pipino, C.; Mandatori, D.; et al. Anti-inflammatory Role of Carotenoids in Endothelial Cells Derived from Umbilical Cord of Women Affected by Gestational Diabetes Mellitus. Oxid. Med. Cell. Longev. 2019, 2019, 1-11. [CrossRef]

31. Mignani, A.G.; Ciaccheri, L.; Ottevaere, H.; Thienpont, H.; Conte, L.; Marega, M.; Cichelli, A.; Attilio, C.; Cimato, A. Visible and near-infrared absorption spectroscopy by an integrating sphere and optical fibers for quantifying and discriminating the adulteration of extra virgin olive oil from Tuscany. Anal. Bioanal. Chem. 2011, 399, 1315-1324. [CrossRef]

32. Del Boccio, P.; Rossi, C.; di Ioia, M.; Cicalini, I.; Sacchetta, P.; Pieragostino, D. Integration of metabolomics and proteomics in multiple sclerosis: From biomarkers discovery to personalized medicine. Proteom. Clin. Appl. 2016, 10, 470-484. [CrossRef] [PubMed]

33. Liberatore, L.; Procida, G.; D'Alessandro, N.; Cichelli, A. Solid-phase extraction and gas chromatographic analysis of phenolic compounds in virgin olive oil. Food Chem. 2001, 73, 119-124. [CrossRef]

34. Cichelli, A.; Riciputi, Y.; Cerretani, L.; Caboni, M.F.; d'Alessandro, N. Glycidols Esters, 2-Chloropropane-1,3-Diols, and 3-Chloropropane-1,2-Diols Contents in Real Olive Oil Samples and their Relation with Diacylglycerols. JAOCS, J. Am. Oil Chem. Soc. 2020, 97, 15-23. [CrossRef]

35. Khadangi, F.; Azzi, A. Vitamin E-The Next 100 Years. IUBMB Life 2019, 71, 411-415. [CrossRef] [PubMed] 
36. Koch, W. Dietary Polyphenols-Important Non-Nutrients in the Prevention of Chronic Noncommunicable Diseases. A Systematic Review. Nutrients 2019, 11, 1039. [CrossRef] [PubMed]

37. Del Carlo, M.; Fusella, G.C.; Pepe, A.; Sergi, M.; Di Martino, M.; Mascini, M.; Martino, G.; Cichelli, A.; Di Natale, C.; Compagnone, D. Novel oligopeptides based e-nose for food quality control: Application to extra-virgin olive samples. Qual. Assur. Saf. Crop. Foods 2014, 6, 309-317. [CrossRef]

38. Kuhlmann, J. Determination of bound 2,3-epoxy-1-propanol (glycidol) and bound monochloropropanediol (MCPD) in refined oils. Eur. J. Lipid Sci. Technol. 2011, 113, 335-344. [CrossRef]

39. Andres, S.; Appel, K.E.; Lampen, A. Toxicology, occurrence and risk characterisation of the chloropropanols in food: 2-Monochloro-1,3-propanediol, 1,3-dichloro-2-propanol and 2,3-dichloro-1-propanol. Food Chem. Toxicol. 2013, 58, 467-478. [CrossRef]

40. Zwagerman, R.; Overman, P. A novel method for the automatic sample preparation and analysis of 3-MCPD-, 2-MCPD-, and glycidylesters in edible oils and fats. Eur. J. Lipid Sci. Technol. 2016, 118, 997-1006. [CrossRef]

41. Pattara, C.; Salomone, R.; Cichelli, A. Carbon footprint of extra virgin olive oil: A comparative and driver analysis of different production processes in Centre Italy. J. Clean. Prod. 2016, 127, 533-547. [CrossRef]

42. Pattara, C.; Russo, C.; Antrodicchia, V.; Cichelli, A. Carbon footprint as an instrument for enhancing food quality: Overview of the wine, olive oil and cereals sectors. J. Sci. Food Agric. 2017, 97, 396-410. [CrossRef] [PubMed]

43. European Parliament \& Council Regulation (EC) No 1924/2006 of the European Parliament and the of the Council on nutrition and health claims made on foods. Off. J. Eur. Union 2006, 404, 9-25.

44. Cheng, W.W.; Liu, G.Q.; Wang, L.Q.; Liu, Z.S. Glycidyl Fatty Acid Esters in Refined Edible Oils: A Review on Formation, Occurrence, Analysis, and Elimination Methods. Compr. Rev. Food Sci. Food Saf. 2017, 16, 263-281. [CrossRef]

45. MacMahon, S.; Begley, T.H.; Diachenko, G.W. Occurrence of 3-MCPD and glycidyl esters in edible oils in the United States. Food Addit. Contam. Part A Chem. Anal. Control. Expo Risk Assess. 2013, 30, 2081-2092. [CrossRef] [PubMed]

46. Cerretani, L.; Giuliani, A.; Maggio, R.M.; Bendini, A.; Toschi, T.G.; Cichelli, A. Rapid FTIR determination of water, phenolics and antioxidant activity of olive oil. Eur. J. Lipid Sci. Technol. 2010, 112, 1150-1157. [CrossRef]

47. Guarino, F.; Falcone, G.; Stillitano, T.; De Luca, A.I.; Gulisano, G.; Mistretta, M.; Strano, A. Life cycle assessment of olive oil: A case study in southern Italy. J. Environ. Manag. 2019, 238, 396-407. [CrossRef]

48. Rinaldi, S.; Barbanera, M.; Lascaro, E. Assessment of carbon footprint and energy performance of the extra virgin olive oil chain in Umbria, Italy. Sci. Total Environ. 2014, 482-483, 71-79. [CrossRef]

49. Del Borghi, A.; Gallo, M.; Strazza, C.; Del Borghi, M. An evaluation of environmental sustainability in the food industry through Life Cycle Assessment: The case study of tomato products supply chain. J. Clean. Prod. 2014, 78, 121-130. [CrossRef]

50. Page, G.; Ridoutt, B.; Bellotti, B. Carbon and water footprint tradeoffs in fresh tomato production. J. Clean. Prod. 2012, 32, 219-226. [CrossRef]

51. Schönhart, M.; Penker, M.; Schmid, E. Sustainable local food production and consumption: Challenges for implementation and research. Outlook Agric. 2009, 38, 175-182. [CrossRef]

52. Prüss-Ustün, A.; Wolf, J.; Corvalán, C.; Neville, T.; Bos, R.; Neira, M. Diseases due to unhealthy environments: An updated estimate of the global burden of disease attributable to environmental determinants of health. J. Public Health 2017, 39, 464-475. [CrossRef] [PubMed]

53. Annunziata, A.; Vecchio, R. Organic Farming and Sustainability in Food Choices: An Analysis of Consumer Preference in Southern Italy. Agric. Agric. Sci. Procedia 2016, 8, 193-200. [CrossRef]

54. Cohen, D.A.C.; Lesser, L.I.L. I HHS Public Access. Physiol. Behav. 2017, 176, 139-148.

55. Johansson Blight, K. Can Asylum Seeking Be 'Managed' Ethically? In Public Health Ethics: Cases Spanning the Globe; Barrett, D.H., Bolan, G., Dawson, A., Ortmann, L., PAHO, C.S., Eds.; Springer: Gewerbestr, Switzerland, 2016.

56. Vo-Nguyen, B.Q.; Kong, H.Y. Symbol Error Rate expression for decode-and-forward relaying using generalized selection combining over Rayleigh fading channels. IEICE Trans. Commun. 2009, E92-B, 1369-1372. [CrossRef] 
57. Guyomard, H.; Darcy-Vrillon, B.; Esnouf, C.; Marin, M.; Russel, M.; Guillou, M. Eating patterns and food systems: Critical knowledge requirements for policy design and implementation. Agric. Food Secur. 2012, 1, 1-21. [CrossRef]

58. Egnell, M.; Ducrot, P.; Touvier, M.; Allès, B.; Hercberg, S.; Kesse-Guyot, E.; Julia, C. Objective understanding of Nutri-Score Front-Of-Package nutrition label according to individual characteristics of subjects: Comparisons with other format labels. PLoS ONE 2018, 13, e0202095. [CrossRef] [PubMed]

59. Darmon, N.; Vieux, F.; Maillot, M.; Volatier, J.L.; Martin, A. Nutrient profiles discriminate between foods according to their contribution to nutritionally adequate diets: A validation study using linear programming and the SAIN, LIM system. Am. J. Clin. Nutr. 2009, 89, 1227-1236. [CrossRef] [PubMed]

60. Mostaghel, R.; Oghazi, P. Elderly and technology tools: A fuzzyset qualitative comparative analysis. Qual. Quant. 2017, 51, 1969-1982. [CrossRef] [PubMed]

(C) 2020 by the authors. Licensee MDPI, Basel, Switzerland. This article is an open access article distributed under the terms and conditions of the Creative Commons Attribution (CC BY) license (http://creativecommons.org/licenses/by/4.0/). 